\title{
PENGENALAN SCIENCE EXPERIMENT PEMBUATAN ICE CREAM KEPADA ANAK USIA DINI DI KABUPATEN SERANG BANTEN
}

\author{
Widyawati \\ Universitas Banten Jaya, J1 Syech Nawawi Albantani Serang, Banten, Indonesia \\ Email: widyawati@unbaja.ac.id
}

\begin{abstract}
Tinggar Village is one of the villages located in the Curug sub-district, where the area is located to the east of Serang City, Banten. One of the villages in the Tinggar village is Jengkol Village. In Jengkol Village there is a school named Raudhatul Athfal Bani Daud Al-Islami. Preschool which contains approximately 20 students. some students still have difficulties in accepting the learning process such as lack of courage in opinion and creativity, some students are still shy (lack of confidence), there are some students who are still experiencing problems in gross and fine motor development. Therefore, this service will carry out activities aimed at increasing students' self-confidence and motoric development. The activity was carried out on August 19, 2021 at 10.00 WIB with a total of nine students. The implementation stages are the online preparation stage (google meet), the first conditioning stage, the preparation of the tools and materials needed, the implementation stage, and implementation review stage. The result is the implementation of activities to improve the development of students which can be seen from the implementation of activities, namely students are able to be more confident in expressing opinions and asking questions. Students can increase their knowledge about changing the shape of a liquid into a solid as a form of additional knowledge about science experiments. Furthermore, students can be trained how to express emotions by identifying and explaining the flavors produced from the ice cream or tasting raw materials such as knowing the taste of salt.
\end{abstract}

Keywords: Banten; Ice Cream; Motoric; PAUD; Science Experiments.

\begin{abstract}
ABSTRAK
Kelurahan Tinggar merupakan salah satu kelurahan yang terletak di wilayah kecamatan Curug, dimana wilayah tersebut terletak di sebelah Timur Kota Serang, Banten. Salah satu Kampung yang berada dikelurahan Tinggar adalah Kampung Jengkol. Di Kampung jengkol terdapat salah satu sekolah yang Bernama Raudhatul Athfal Bani Daud Al-Islami. Sekolah tersebut terdapat Pendidikan Anak Usia Dini (PAUD) yang beisikan kurang lebih 20 peserta didik. beberapa peserta didik masih mengalami kesulitan dalam menerima proses pembelajaran seperti kurangnya keberanian dalam berpendapat dan berkreasi, beberapa peserta didik masih ada yang pemalu (kurang percaya diri), terdapat beberapa peserta didik yang masih mengalami kendala dalam perkembangan motorik kasar dan halus. Oleh karena itu pengabdian ini akan melakukan kegiatan bertujuan untuk meningkatkan rasa percaya diri dan perkembangan motorik peserta didik. Kegiatan tersebut dilaksanakan pada tanggal 19 Agustus 2021 Pukul 10.00 WIB dengan jumlah peserta didik sebanyak sembilan orang. Tahapan pelaksanaan adalah tahapan persiapan secara daring (google meet), tahapan pengkondisian pertama, Persiapan alat dan bahan yang dibutuhkan, tahap pelaksanaan, tahap penutupan dan tahap review pelaksanaan. Adapun hasil dari kegiatan adalah terlaksananya kegiatan untuk meningkatkan perkembangan peserta didik yang dapat dilihat dari jalannya pelaksanaan kegiatan, yaitu peserta didik mampu lebih percaya diri dalam mengemukakan pendapat dan bertanya. Peserta didik dapat menambah pengetahuannya mengenai perubahan bentuk dari zat cair menjadi zat padat sebagai bentuk penambahan ilmu mengenai percobaam science. Untuk selanjutnya peserta didik dapat dilatih bagaimana mengekspresikan emosi dengan cara mengidentifikasi dan menjelaskan tentang rasa yang dihasilkan dari es krim tersebut atau merasakan bahan baku seperti mengetahui rasa garam.
\end{abstract}

Kata kunci: Banten; Es Krim; Motorik; PAUD; Science Experiment. 


\section{PENDAHULUAN}

Pendidikan Anak Usia Dini (PAUD) merupakan pendidikan dasar yang berperan penting dalam mengoptimalkan aspek perkembangan pada setiap peserta didik yang memiliki usia 0-6 tahun (Fauziddin, Peningkatan Kemampuan Kerja Sama melalui Kegiatan Kerja Kelompok Pada Anak Kelompok A TK Kartika Salo Kabupaten Kampar, 2016).

Menurut para ahli psikologi, usia dini hanya datang sekali dan tidak dapat diulang lagi, yang sangat menentukan untuk pengembangan kualitas manusia selanjutnya. Benyamin S, Bloom dkk, berdasarkan hasil pengabdian, mereka mengemukakan bahwa perkembangan intelektual anak terjadi sangat pesat pada tahun-tahun awal kehidupan anak. Sekitar 50\% variabilitas kecerdasan orang dewasa sudah terjadi ketika anak berusia 4 tahun. Peningkatan $30 \%$ berikutnya terjadi pada usia 8 tahun, dan $20 \%$ sisanya pada pertengahan atau akhir dasawarsa kedua.(Muhiyatul Huliyah 2016). Perkembangan tersebut diantaranya adalah fisik motorik, sosial emosional (sikap dan perilaku serta agama), bahasa, moral dan agama, dan kognitif, sesuai dengan keunikan dan tahap-tahap perkembangan yang dilalui oleh anak usia dini. Pengoptimalan aspekaspek perkembangan pada anak usia dini dapat dilakukan melalui berbagai cara, salah satunya dengan cara mengikutsertakan anak dalam Pendidikan Anak Usia Dini (PAUD). Didasarkan pada Peraturan Menteri Pendidikan dan Kebudayaan Republik Indonesia (Permendikbud) Nomor 137 tahun 2014, PAUD dilaksanakan pada suatu lembaga pendidikan dalam bentuk Taman Kanakkanak (TK)/Raudatul Athfal (RA)/Bustanul Athfal (BA), Kelompok Bermain (KB), Taman Penitipan Anak (TPA), dan Satuan PAUD Sejenis (SPS). (Wulandari and Purwanta 2020).

Pendidikan Anak Usia Dini bertujuan untuk mengembangkan seluruh potensi anak (the whole child) agar kelak dapat berfungsi sebagai manusia yang utuh. Anak dapat dipandang sebagai individu yang baru mengenal dunia. Anak belum mengetahui tata krama, norma, etika dan berbagai hal tentang dunia. Anak juga sedang belajar berkomunikasi dengan orang lain dan belajar juga dalam memahami orang lain. Anak perlu dibimbing agar mampu memahami berbagai hal tentang dunia dan isinya. Ia juga perlu dibimbing agar memamhami berbagai fenomena alam agar dapat melakukan keterampilan-keterampilan yang dibutuhkan untuk hidup di masyarakat. Interaksi anak dengan benda dan orang lain diperlukan untuk belajar agar anak mampu mengembangkan kepribadian, watak, dan akhlak yang mulia. Usia dini merupakan saat yang amat berharga untuk menanamkan nilai-nilai nasionalisme, kebangsaan, agama, etika, moral dan sosial yang berguna untuk kehidupannya.(Aryani 2015)

Tujuan Pendidikan Anak Usia Dini (PAUD) berdasarkan Undang-Undang nomor 20 tahun 2003 tentang sistem pendidikan nasional dinyatakan bahwa pendidikan anak usia dini adalah sebagai suatu upaya pembinaan yang ditujukan kepada anak sejak lahir sampai dengan usia enam tahun yang dilakukan melalui pemberian rangsangan pendidikan untuk membantu 
pertumbuhan dan perkembangan jasmani dan rohani agar anak memiliki kesiapan dalam memasuki pendidikan lebih lanjut (Fauziddin \& Mufarizuddin, Useful of Clap Hand Games for Optimalize Cogtivite Aspects in Early Childhood Education, 2018).

Kelurahan Tinggar merupakan salah satu kelurahan yang terletak di wilayah kecamatan Curug, dimana wilayah tersebut terletak di sebelah Timur Kota Serang, Kelurahan Tinggar terdiri dari 4 RW dan 19 RT dengan jumlah penduduk 5960 terdiri dari 1311 KK, Kelurahaan Tinggar berbatasan wilayah Utara yaitu dengan Kelurahan Sukalaksana, Selatan berbatasan dengan Kelurahan Negara Padang, Barat berbatasan dengan Kelurahan Cilowong, dan Timur berbatasan dengan Kelurahan Pancalaksana. Luas Kelurahan Tinggar yaitu sebesar 2,86 Ha.

Salah satu kampung yang berada di Kelurahan Tinggar yaitu Bernama Kampung Jengkol. Di Kampung jengkol terdapat salah satu sekolah yang Bernama Raudhatul Athfal Bani Daud AlIslami. Sekolah tersebut terdapat Pendidikan Anak Usia Dini (PAUD) yang beisikan kurang lebih 20 peserta didik. beberapa peserta didik masih mengalami kesulitan dalam menerima proses pembelajaran seperti kurangnya keberanian dalam berpendapat dan berkreasi, beberapa peserta didik masih ada yang pemalu (kurang percaya diri), terdapat beberapa peserta didik yang masih mengalami kendala dalam perkembangan motorik kasar dan halus.

Berdasarkan permasalahan tersebut maka pengabdian ini akan menggunakan teknik bermain (belajar sambal bermain), dengan cara mengenalkan science experiment pembuatan ice cream kepada anak usia dini di Kampung Jengkol Kelurahan Tinggar Kecamatan Curug Kabupaten Serang Banten. Tujuan penerapan teknik bermain sambil belajar bagi anak usia dini salah satunya adalah untuk menstimulasi otak anak dalam jangka panjang agar dalam memorinya selalu dipenuhi oleh kegiatan-kegiatan yang memberi kesan positif dan tentunya menyenangkan bagi anak. Tujuan bermain tersebut pada dasarnya diarahkan untuk mengembangan multiple intelligences anak. (Nurdiani 2013). Hasil pengabdian ini diharapkan mampu meningkatkan perkembangan peserta didik yang berada di PAUD Raudhatul Athfal Bani Daud Al-Islami.

Pengabdian ini mendapatakan referensi berdasarkan pengabdian lainnya yaitu, tentang pengenalan permainan sains bagi siswa SDK Tes Kecamatan Bikomi Utara Timur Tengah Utara yang dilakukan oleh vinsensia (Sila, Manlea, \& Kolo, 2018). Pengabdian pendukung lainnya adalah tentang belajar asik dengan funscience bagi anak-anak dan calon pendidik sekolah dasar (Septiani \& Rani, 2020). Pengabdian lain dilakukan oleh Fiorentina Maria Panda tentang peningkatan kemampuan melakukan praktikum IPA (sains) pada guru SD melalui percobaan sederhana (Panda \& Koirewoa, 2017). 


\section{METODE PELAKSANAAN}

Pelaksanaan diawali dengan persiapan yang dilakukan oleh panitia melalui laman daring (google meet) dengan jumlah peserta sebanyak sebelas orang untuk membahas beberapa hal yang terkait dengan pelaksanaan. Adapun beberapa rincian tersebut adalah: (1) Penentuan lokasi dan waktu pelaksanaan, (2) Proses pemberkasan, (3) Tahapan peridzinan, (4) pendataan peserta didik yang akan turut serta dalam proses pelaksanaan, (5) Mengunjungi lokasi pelaksanaan untuk tahapan pengkondisian, (6) Persiapan alat dan bahan yang dibutuhkan selama proses pengabdian dilaksanakan, (7) Tahapan pelaksanaan, (8) Review pelaksanaan.

Kegiatan tersebut dilaksanakan pada tanggal 19 Agustus 2021 Pukul 10.00 WIB sampai dengan pukul 12.00 WIB. Dengan jumlah peserta didik sebanyak Sembilan orang. Dengan lokasi pelaksanaan yaitu di PAUD Raudhatul Athfal Bani Daud Al-Islami Kampung Jengkol Kelurahan Tinggar Kecamatan Curug Kabupaten Serang Provinsi Banten - Indonesia.

Tahapan awal pelaksanaan peserta didik memperoleh pengarahan secara sederhana yang dikemas seperti bermain. Sebelumnya dilakukan proses pengenalan terlebih dahulu dari pemateri, dengan rincian kegiatan sebagai berikut: (1) Penataan lingkungan main, (2) Penyambutan anak, (3) Main pembukaan, (4) Kegiatan inti, (5) Mencoba hasil percobaan, (6) Kegiatan penutup.

\section{HASIL DAN PEMBAHASAN}

Kegiatan pengenalan science experiment pembuatan ice cream kepada anak usia dini di Kampung Jengkol Kelurahan Tinggar Kecamatan Curug Kabupaten Serang Banten dilaksanakan selama 1 hari dengan durasi 1 jam pelaksanaan untuk kegiatan inti. Untuk kegiatan dilaksanakan sebanyak Sembilan peserta didik. Berikut ini merupakan detail pelaksanaan yang dilaksanakan diantaranya adalah sebagai berikut:

1. Tahapan persiapan secara daring (google meet)

Dalam tahap ini pembahasan mengenai (1) Penentuan lokasi dan waktu pelaksanaan, (2) Proses pemberkasan, (3) Tahapan peridzinan. Lokasi yang dituju adalah Sekolah Raudhatul Athfal Bani Daud Al-Islami. Sekolah tersebut terdapat Pendidikan Anak Usia Dini (PAUD) yang beisikan kurang lebih 20 peserta didik. beberapa peserta didik masih mengalami kesulitan dalam menerima proses pembelajaran seperti kurangnya keberanian dalam berpendapat dan berkreasi, beberapa anak masih ada yang pemalu (kurang percaya diri), terdapat beberapa anak yang masih mengalami kendala dalam perkembangan motorik kasar dan halus. Sekolah tersebut berada pada salah satu kampung yang berada di Kelurahan Tinggar yaitu Bernama Kampung Jengkol. Waktu pelaksanaan adalah pada tanggal 19 Agustus 2021 Pukul 10.00 WIB sampai dengan pukul 12.00 WIB. Yang diikuti oleh Sembilan (9) orang peserta didik. Tahapan pemberkasan adalah dilakukan dengan menyiapkan surat peridzinan mengenai tempat pelaksanaan pengabdian yang diberikan 
kepada kepala Raudhatul Athfal Bani Daud Al-Islami Kampung Jengkol kemudian dilanjutkan dengan pembuatan surat izin kesediaan orang tua/wali agar mengidzinkan anaknya untuk mengikuti kegiatan pengabdian tersebut.

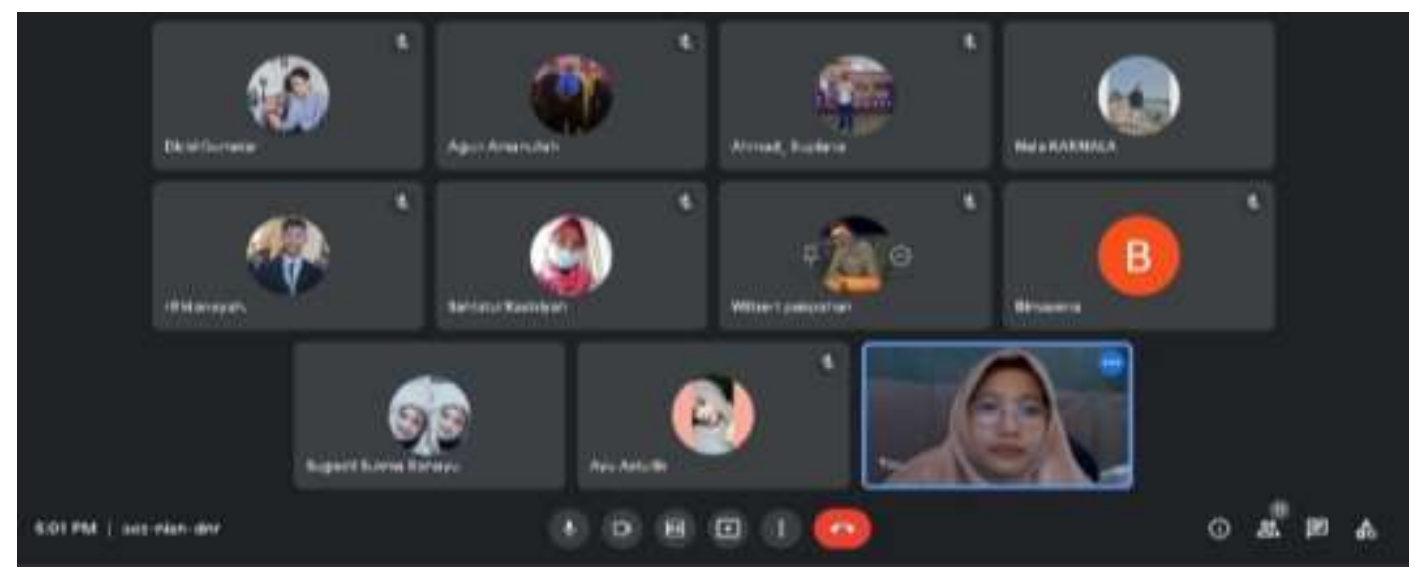

Gambar 1. Tahapan Rapat Persiapan

Berikut ini merupakan agenda kegiatan yang dilaksanakan tertera pada Tabel 1 dibawah ini:

Tebel 1. Agenda Kegiatan

\begin{tabular}{|c|c|c|}
\hline Waktu & Kegiatan & Keterangan \\
\hline $\begin{array}{l}\text { Jum'at, } 23 \\
\text { Juli } 2021\end{array}$ & $\begin{array}{c}\text { Rapat Persiapan Pengabdian } \\
\text { melalui zoom meet }\end{array}$ & $\begin{array}{l}\text { Kegiatan Rapat dilaksanakan pada } \\
\text { jam } 17.00 \text { WIB dengan pembahasan } \\
\text { mekanisme pelaksanaan pengabdian. }\end{array}$ \\
\hline $\begin{array}{l}\text { Kamis, } 12 \\
\text { Agustus } \\
2021\end{array}$ & $\begin{array}{c}\text { Pembuatan surat izin } \\
\text { pelaksanaan pengabdian }\end{array}$ & $\begin{array}{l}\text { Surat izin pelaksanaan pengabdian } \\
\text { diberikan kepada kepala Raudhatul } \\
\text { Athfal Bani Daud Al-Islami } \\
\text { Kampung Jengkol. }\end{array}$ \\
\hline $\begin{array}{l}\text { Senin, } 16 \\
\text { Agustus } \\
2021\end{array}$ & $\begin{array}{l}\text { Pembuatan surat izin orang } \\
\text { tua/wali }\end{array}$ & $\begin{array}{l}\text { Surat izin diberikan kepada orang } \\
\text { tua/wali siswa agar mengizinkan } \\
\text { anaknya untuk mengikuti kegiatan } \\
\text { pengabdian. }\end{array}$ \\
\hline
\end{tabular}

2. Tahapan Pengkondisian Pertama

Pada tahap ini panitia mengunjungi lokasi untuk melakukan proses peridzinan, pendataan peserta didik yang akan turut serta dalam proses pelaksanaan. 


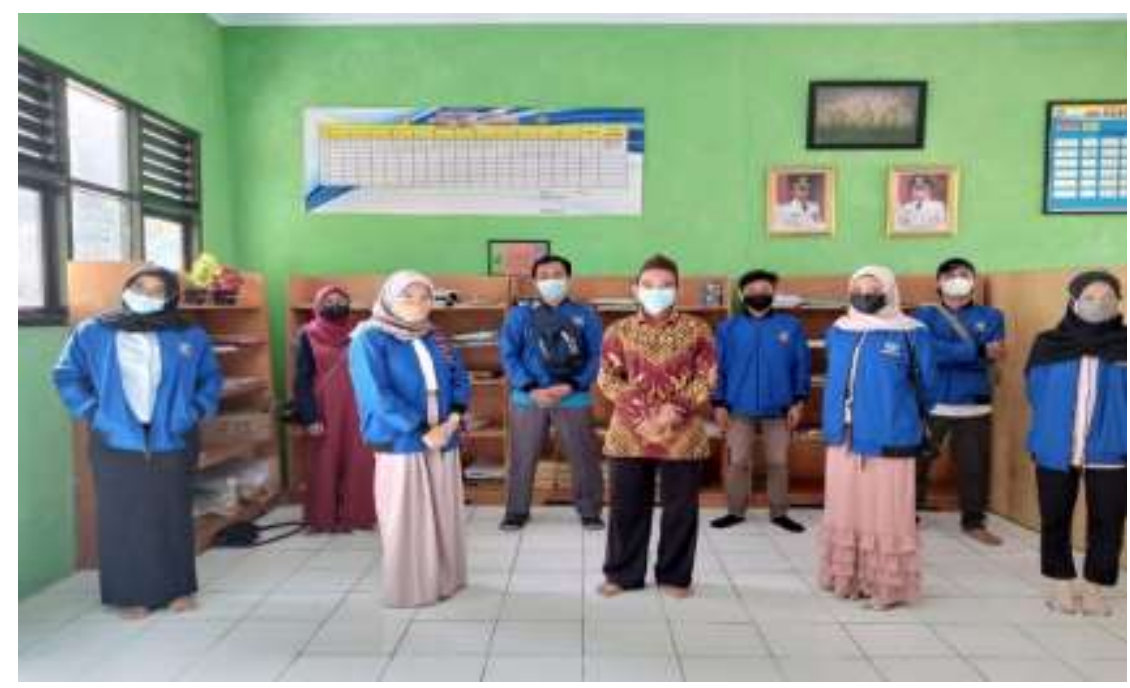

Gambar 2. Tahapan Peridzinan untuk Pelaksanaan Kegiatan

3. Persiapan Alat dan Bahan yang Dibutuhkan

Berikut ini merupakan bahan serta alat yang dibutuhkan selama proses kegiatan berlangsung dapat dilihat pada Tabel 2.

Tabel 2. Alat dan Bahan yang Dibutuhkan

\begin{tabular}{cll}
\hline No. & \multicolumn{1}{c}{ Alat } & \multicolumn{1}{c}{ Bahan } \\
\hline 1 & Plastik clip besar ukuran $30 \times 40$ & Susu kotak cair (susu UHT) ukuran kecil (125 ml) \\
\hline 2 & Plastik clip kecil ukuran 7x10 & Es Batu \\
\hline 3 & Gunting & Garam dapur \\
\hline 4 & Sendok & \\
\hline 5 & Cup ice cream/gelas plastik & \\
\hline
\end{tabular}

4. Tahap Pelaksanaan

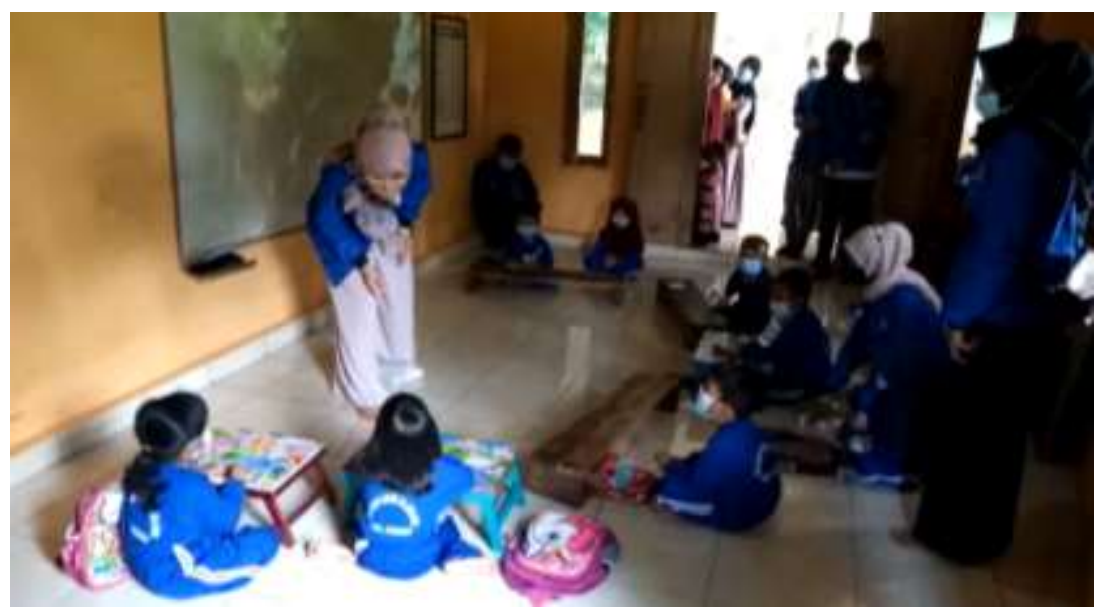

Gambar 3. Kegiatan Diskusi dengan Peserta Didik 
Gambar 3 merupakan tahapan pelaksanaan pembuatan ice cream dimana peserta didik diberikan pengarahan. Selanjutnya peserta didik diberikan satu paket alat dan bahan yang akan digunakan. Peserta didik diminta membuka pelastik klip untuk melatih motorik kasar dan halus. Selanjutnya peserta didik diminta untuk memasukan es batu kedalam pelastik. Tahapan selanjutnya membuka bungkusan pelastik garam dengan latihan menggunting (dalam pengawasan) dan memasukan garam tersebut kedalam pelastik yang berisikan es batu. Selanjutnya peserta didik diminta untuk memasukan susu kedalam pelastik clip yang lebih kecil dan menutupnya kembali. Tahapan selanjutnya susu tersebut dimasukan kedalam pelastik yang besar dan dilakukan tahapan mengkocok sampai susu berubah dari cair menjadi beku untuk melatih perkembangan motorik kasar dan halus peserta didik. Tahapan akhir adalah susu yang sudah berubah menjadi ice cream dimasukan kedalam gelas cup.

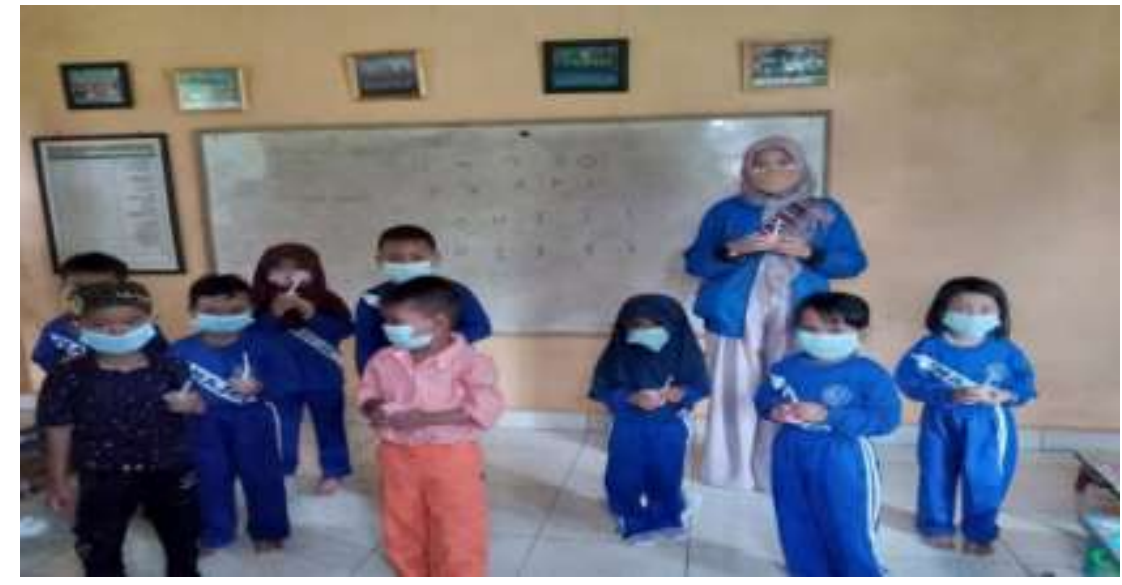

Gambar 4. Kegiatan Dokumentasi Hasil Percobaan

Gambar 4 menjelaskan mengenai foto Bersama yang dilakukan setelah semua peserta didik berhasil membuat percobaan science sederhana. Dari Sembilan peserta didik semua berhasil membuat es krim yang berbahan baku susu UHT. Para pserta diminta untuk berkelompok menjadi beberapa kelompok untuk mengurangi kerumunan dengan 1 orang pendamping menangani 2 peserta didik dengan protokol kesehatan. Peserta didik diminta untuk menggunakan masker dan menggunakan cairan antiseptik pada lengan mereka. Tahap selanjutnya adalah peserta didik diberikan beberapa penjelasan mengenai perbedaan antara alat dan baham, kemudian wujud zat dari bahan percobaan dan perubahannya. Peserta didik juga diberikan beberapa penjelasan menganai rasa, serta perubahan suhu dari bahan yang digunakan tersebut. 
5. Tahap Penutupan

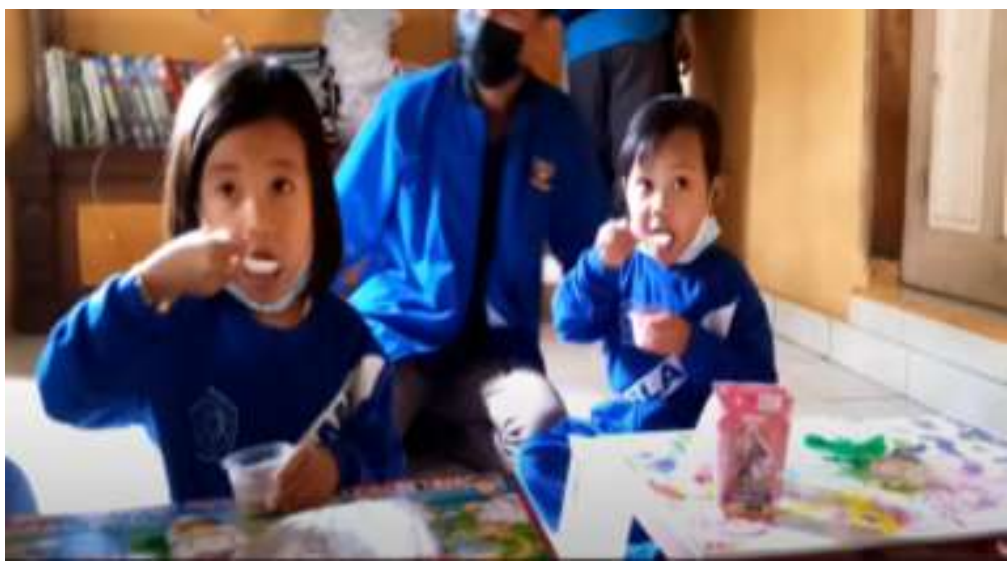

Gambar 5. Kegiatan Merasakan Hasil Ice Cream

Gambar 5 merupakan tahapan dimana peserta didik diminta untuk merasakan hasil yang dibuat untuk mengetahui bagaimana rasa dari ice cream tersebut. Tahap terakhir adalah peserta didik diminta untuk menjelaskan perasaan yang mereka rsakan mengenai pengalaman membuat es krim sebagai bentuk percobaan science sederhana, dari tahapan tersebut dapat diketahui bagaiamana dan sejauh mana tujuan percobaan tersebut dapat dilaksanakan.

6. Review Pelaksanaan

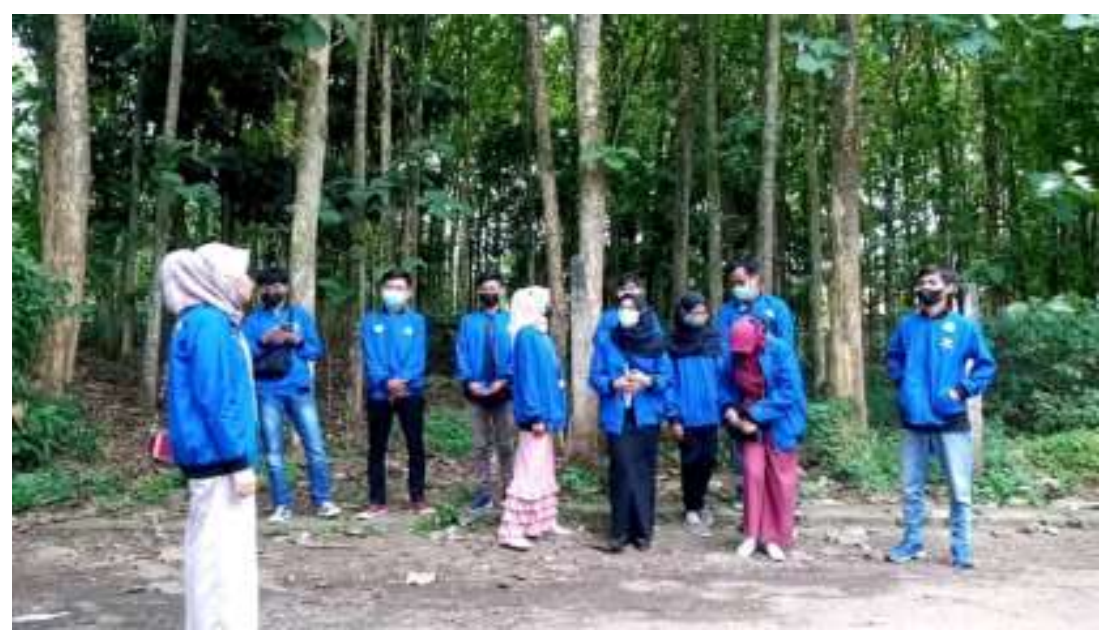

Gambar 6. Kegiatan Review Pelaksanaan

Gambar 6 adalah tahapan akhir dengan mengadakan review dari kegiatan pelaksanaan yang sebelumnya telah dilaksanakan untuk mengetahui kekurangan jalannya pelaksanaan dan penutupan panitia dari program kerja tersebut. 


\section{KESIMPULAN}

Berdasarkan hasil kegiatan pengabdian yang dilakukan maka dapat disimpulkan bahwa kegiatan tersebut dapat meningkatkan perkembangan peserta didik yang dapat dilihat dari jalannya pelaksanaan kegiatan, yaitu peserta didik mampu lebih percaya diri dalam mengemukakan pendapat dan bertanya. Peserta didik dapat menambah pengetahuannya mengenai perubahan bentuk dari zat cair menjadi zat padat sebagai bentuk penambahan ilmu mengenai percobaam science. Untuk selanjutnya peserta didik dapat dilatih bagaimana mengekspresikan emosi dengan cara mengidentifikasi dan menjelaskan tentang rasa yang dihasilkan dari ice cream tersebut atau merasakan bahan baku seperti mengetahui rasa garam.Harapan dari pelaksanaan pengabdian ini adalah mampu mengoptimalkan aspek perkembangan pada setiap peserta didik.

\section{UCAPAN TERIMA KASIH}

Penulis mengucapkan rasa syukur untuk dukungan pelaksanaan pengabdian ini yaitu kepada Kelompok 10 Kuliah Kerja Mahasiswa (KKM) Universitas Bnaten Jaya tahun pelaksanaan Genap 2020/2021.

\section{DAFTAR PUSTAKA}

Aryani, Nini. (2015). Konsep Pendidikan Anak Usia Dini Dalam Perspektif Pendidikan Islam. POTENSIA: Jurnal Kependidikan Islam 1 (2): 213-27. http://ejournal.uinsuska.ac.id/index.php/potensia/article/view/3187.

Fauziddin, M. (2016). Peningkatan Kemampuan Kerja Sama melalui Kegiatan Kerja Kelompok Pada Anak Kelompok A TK Kartika Salo Kabupaten Kampar. Jurnal PGPAUD STKIP Pahlawan Tuanku Tambusai Riau, 29-45.

Fauziddin, M., \& Mufarizuddin. (2018). Useful of Clap Hand Games for Optimalize Cogtivite Aspects in Early Childhood Education. Jurnal Obsesi Prodi PG-PAUD FIP UPTT 2018, 162-169.

Muhiyatul, H. (2016). Hakikat Pendidikan Anak Usia Dini Jalur Pendidikan Informal. Pendidikan Guru Raudlatul Athfal 1 (1): 61-62.

Nurdiani, Y. (2013). Penerapan Prinsip Bermain Sambil Belajar Dalam Mengembangkan Multiple Inteligencia Pada Pendidikan Anak Usia Dini (Study Kasus Di PAUD Daarul Piqri Kelurahan Leuwigajah Cimahi Selatan). Empowerment 2 (2): 85-93.

Panda, F., \& Koirewoa, D. (2017). Peningkatan Kemampuan Melakukan Praktikum IPA (Sains) Pada Guru SD Melalui Percobaan Sederhana. Jurnal Pengabdian Papua, 59-62. 
Septiani, D., \& Rani, K. (2020). Belajar Asik dengan Funscience Bagi Anak-anak dan Calon Pendidik Sekolah Dasar. Amal Ilmiah : Jurnal Pengabdian Kepada Masyarakat, 102107.

Sila, V., Manlea, H., \& Kolo, S. (2018). Pengenalan Permainan Sains Bagi Siswa SDK Tes Kecamatan Bikomi Utara, Timor Tengah Utara. Jurnal Cendana: Jurnal Pengabdian Masyarakat, 11-18.

Wulandari, Hesti, and Edi Purwanta. (2020). Pencapaian Perkembangan Anak Usia Dini Di Taman Kanak-Kanak Selama Pembelajaran Daring Di Masa Pandemi Covid-19. Jurnal Obsesi: Jurnal Pendidikan Anak Usia Dini 5 (1): 452. https://doi.org/10.31004/obsesi.v5i1.626. 